\section{Climital a}

\section{MEDICAL, SURGICAL, OBSTETRICAL, AND THERAPEUTICAL.}

\section{NOTE ON A CASE OF HERNIA OF THE VERMIFORM} APPENDIX INTO AN OLD FEMORAL SAC.

By Thomas F. Chavasse, M.C. Edin., F.R.C.S. Edin. \& ENG.,

SENIOR SURGEON TO THX BIRMINGHAM GENERAL HOSPITAL.

THE case here recorded resembles in many particulars those recently described by Mr. Edmund Owen and Mr. W. H. Battle. ${ }^{3}$

On May 8th, 1899, I saw in consultation with Mr. Arthur Jackson of Smethwick, Birmingham, a patient, aged 65 years, a widow, and the mother of 10 children, who for some years had suffered from a small umbilical hernia for which a suitable belt and pad were worn with advantage. She was also afflicted with rheumatoid arthritis of the hip joint and she had noticed for some years that from time to time a substance made its appearance in the position of a femoral hernia on the right side which was most marked if any straining took place during the acts of micturition and defecation. During the first week in May she became aware that the lump was persistent, that it was larger than ever before, and also that it was hard; she therefore consulted Mr. Jackson, who sent her to bed and applied heat. As no appreciable change took place a consultation was held. On examination a fixed tumour was found to exist at the base of Scarpa's triangle, about three inches long, overlapping Poupart's ligament and tailing off towards the pubes. This was hard to the touch, irreducible and painless, with a suggestion of deep-seated fluctuation. There was no impulse on coughing and the skin was unaffected. The bowels acted regularly and freely. The diagnosis apparently lay between femoral adenitis and some inflamed omentum in an old femoral sac. As the patient was adverse to any exploratory operation an expectant line of treatment was adopted and under the influence of rest and heat the lump gradually lessened in size. On May 19 th a second consultation was held. The tumour was then of about the size of a Tangerine orange, soft and fluctuant, but containing in its deeper parts a hard mass which felt like the unsoftened portion of a lymphatic gland. On our urging the necessity of operative interference consent was given. On the following day (May 20th), with the assistance of Mr. Arthur Jackson and Mr. Wilfrid Jackson, I made a longitudinal incision into the tumour which gave exit to about six drachms of a darkcoloured serous fluid and revealed an old femoral sac one-eighth of an inch thick containing a much-congested appendix, three inches in length and of the thickness of an ordinary forefinger, curled up with the free end to the right. At first sight this looked like a knuckle of small intestine. Its mesocolon lay to the outer side and a small mass of adherent omentum lay to the inner side. The appendix was removed in the ordinary manner up to the crural ring and the stump was pushed back into the peritoneal cavity. The omentum adherent to the inner side of the sac was dissected off ligatured, and remored. The sac itself was then freed to its neck, ligatured, and cut away, and the skin incision was closed by sutures after the insertion of an iodoform gauze drain. No unfavourable symptoms followed the operation.

This case apparently bears out the contention of $\mathrm{Mr}$. McAdam Eccles that the inflammation of the appendix in these instances often takes place after its prolapse into the hernial sac and that the strangulation is secondary, being caused by the acute inflammatory processes taking place in a confined space. In this patient the crural ring was apparently of about the normal size and the stump of the appendix readily slipped back into the abdominal cavity, showing that its neck was not nipped. Judging by the thickness of the sac and the adhesions of the omentum the hernia had probably been in existence for a long period in an irreducible form. Mr. Jackson states that three weeks before he was first consulted the patient, when assisting to nurse a sick relative, accidentally received a blow in the region of the

1 The Laxcer, May 6th, 1899, pp. 1222, 1227. cæcum and this possibly may have been a contributing factor to the prolapse of the appendix. When removed this organ, especially at its free end, was very codematous and if it had been allowed to remain might eventually have become gangrenous from the effects of the inflammatory exudations. It contained no concretion or other foreign body. As in the cases of Mr. Edmund Owen and Mr. W. H. Battle this patient was a married woman advanced in years and my experience is quite in agreement with that of the former surgeon as to the rarity of this condition, this being the first case which I have ever met with either in my hospital practice or in my private practice.

Birmingham.

\section{NOTES ON A CASE OF ADDISON'S DISEASE TREATED WITH SUPRARENAL EXTRACT.}

By Arthur Foster, M.D., C.M. Edin.

IN October, 1898, I was consulted by a robust woman, aged 38 years, a weaver by trade, for symptoms of wellmarked Addison's disease. She had had three normal labours, the last at 23 years of age. Menstruation began at 14 years of age, and except with the interruptions of pregnancy continued to be perfectly regular up to the age of 28 years at which time she "caught cold" and since then had not had the slightest sign of it. The first symptoms of the disease developed in April, 1898, when she was compelled to give up her employment owing to a feeling of lassitude and debility. This continued to increase and was accompanied by discolouration of the skin, the first place for it to be noticed being the forehead, on which there were several dirty patches which the patient vainly endeavoured to wash off. Her family history was exceptionally good, both parents having lived to over 70 years of age. She had three sisters, all married and having large families, and all past a normal menopause. There was no history of any tuberculous or malignant disease to be found in any of the living or dead members of the family. On examination the only pain complained of was in the back over the region of the suprarenal glands. It had been present for four months. The pulse was small and it varied from 58 to 64 . The heart's impulse was scarcely perceptible and the sounds were decidedly weak. The least exertion caused breathlessness and faintness and on this account the patient was unable to get out of bed. Her stomach was in fair condition, though she had recently had several attacks of vomiting - an unusual occurrence for her. The anterior third of the tongue was pigmented and she had a perfect set of teeth. The pigmentation affected the whole body more or less and was especially well marked on the forehead, neck, arms, and round the nipples The amount and specific gravity of the urine were normal and there was no albumin. On vaginal examination the uterus was felt to be atrophied and the ovaries could not be palpated. The mammæ were small for a woman of her age and build. She was at once given five-grain tabloids of suprarenal gland substance, taking four a day. At the end of a month the pain in the back had disappeared, the pulse averaged 68 , and she was able to sit up for several hours without discomfort. During November she contracted influenza and again became confined to bed. However, in December she recruited, and though she had lost flesh she felt better than she had at any time since she began to take the tabloids. The faintness almost disappeared and the pulse now averaged 80 . She was still taking four or five tabloids a day. A greater quantity produced nausea. At the end of February, 1899, she had an attack of diarrhœa and vomiting accompanied by several severe faints and she again became confined to bed. She continued losing ground until March 15th, when convulsions set in and becoming comatose she died 24 hours later. No post-mortem examination was obtainable.

The points of interest which spring from the case appear to me to be the following. 1. The question whether the early cessation of the ovarian function and that of the suprarenal glands have a common cause. I do not know of any relationship having been shown to take place between the capsules on the one hand and the ovaries on the other; the point is, however, worth keeping in mind. 2. The rare termination of Addison's disease in epileptic fits. 3. The effect of suprarenal gland treatment. 'The patient certainly 
got some relief from it. The pain in the back disappeared and the pulse was quickened. She always expressed herself as feeling better after taking the tabloids; she said that she felt more faint when she missed a day. She took them up to a fortnight before her death. The pigmentation did not appear to be influenced in any way by them.

Blackburn.

\section{NOTES ON A CASE OF "LUPUS LYMPHATICUS" OF THE EYEBALL.}

By David WaLsh, M.D. EdiN.,

PHYSICIAN TO THE WESTERN SKIN HOSPITAI, LONDON.

\section{AND}

Sydney Stephenson, M.B., F.R.C.S. Edin.,

OPHTHALMIC SURGEON TO THE EVELINA MOSPITAL AND THE NORTHEASTERY HOSPITAL FOR CHILDREY.

THE following case is one of such rarity as perhaps to warrant a short account in the pages of THE LANCET. So far as we can ascertain few similar cases have hitherto been recorded in this country. Fortunately there can be no doubt as to the diagnosis, for the patient was shown at the Dermatological Society of Great Britain and Ireland on June 29th, 1898. The diagnosis was there confirmed by the President (Dr. Radcliffe Crocker) and other members present. Dr. Crocker agreed that the case came within the same category as those called by Mr. Hutchinson "lupus lymphaticus "but which he himself called "lymphangiectodes " or " Jymphangioma circumscriptum." The case is briefly as follows.

A single woman, aged 18 years, who was seen by both of us in May, 1898, complained of a disfiguring condition of the right eyeball and lids which had existed since infancy but which had not got worse. The patient's general health was good and she was well nourished. No family history was available. As regards the right eye, externally there was apparent lengthening of the eyebrow, and the eyeball was prominent. The palpebral fissure measured 38 millimetres, as against 26 millimetres in the left eye. The lids were swollen and thickened but could be distinctly pitted on moderately firm pressure. The intermarginal space was twice as broad as was that of the other eye. The cornea was small, the globe was of less size than was that of the sound eye, and there was an external strabismus of $25^{\circ}$. The ocular conjunctiva showed a nævoid and vesicular condition as we have described later in detail in this note. The vision of the left eye equalled $\frac{6}{6}$ (Jaeger). With the right eye the patient could make out the number of fingers held up against a strong light at a distance of one metre. The disc of the right eye was ill-defined, the retinal vessels were large and rather tortuous. Both eyes showed dotted opacities in the lens, less marked in the left eye. Several strands of persistent pupillary membrane were present in the right eye, which presented an external nævoid condition. There were an enlarged caruncle and an enlarged semilunar fold which had a pale cedematous look. The fold was merged above and below in thickened conjunctiva and externally it was continuous with a trans. Iucent and vascular growth on the ocular conjunctiva. This growth consisted of a number of jelly-like elevations, arranged roughly in the shape of a ring round the cornea, leaving a clear space of about one-eighth of an inch at the corneal margin except at its upper segment where the growth impinged on the cornea. These yellowish translucent elevations had numerous punctate hæmorrhagic injections and fine blood-vessels. In places the jelly-like bodies were about one-eighth of an inch in thickness and were pouch-like. The patient stated that the eyelid got black at times and that there used to be a lump sometimes at the inner angle of the orbit. The capillaries on the cheeks were dilated.

The chief interest of this condition lies in its exact resemblance to Mr. Jonathan Hutchinson's "lupus lymphaticus." The jelly-like pouches on the eyeball were clearly varicose lymphatics. It seems possible from the history and from the dilated surface capillaries and congested retinal vessels that the eyelids and orbital contents generally may be affected with a mixed vascular and lymphatic nævus. In that case it is interesting to note the differing appearances of what we must assume to be a common underlying pathological condition. The elephantiasis of the eyelid and the næovus lymphaticus of the eyeball, if this view of common origin be accepted, are possibly two distinct expressions of some congenital local affection of angio-lymphatic type. The present lesion is congenital, non-infective, chronic, and associated with congenital næovid manifestations. Mr. Hutchinson figures a patch at the back of the tongue in a young girl and remarks that the aspect of the mucous membrane exactly resembles that of the skin. The present case does not exactly tally with Mr. Hutchinson's lupus lymphaticus inasmuch as it is apparently non-infective and is not associated with attacks of erysipelatous swelling.

\section{di athirror \\ or}

\section{HOSPITAL PRACTICE,} BRITISH AND FOREIGN.

Nulla autem est alia pro certo noscendi via, nisi quamplurimas et morborum et dissectionum historias, tum aliorum tum proprias collectas habere, et inter se comparare.-MORGagni De Sed. et Caus. Morb., lib. iv. Proœmium.

\section{LONDON HOSPITAL.}

A CASE OF ADDISON'S DISEASE IN WHICH THE BLOODPRESSURE WAS TAKEN TWO DAYS BEFORE DEATH.

(Under the care of Dr. CHARLEwood TURNER.)

THE great value of Hill and Barnard's sphygmometer is that by its use a numerical value can be given to the arterial tension in any case, and it is thus much easier to comparc the tension with that in other cases or with the tension in the same case at another time. The great reduction from 120 to $73 \mathrm{~mm}$. of mercury is very striking. As to the value of suprarenal feeding in Addison's disease a certain number of patients receive much benefit, others for a time improve, while in most of the cases hardly any improvement follows. Sydney Ringer and A. G. Phear have collected the cases in which this treatment was followed. ${ }^{1}$ For the notes of the case we are indebted to Mr. Reginald Wilson and $\mathrm{Mr}$. Harold L. Barnard.

A man, aged 53 years, was admitted to the London Hospital complaining of extreme weakness without wasting. For two years be had been suffering from progressive loss of strength, but he had kept at his work until a fortnight before admission, when he was compelled to give in and take to his bed. In addition to the extreme debility and the irresistible desire to lie down he complained of frontal headache and vertigo associated with nausea and vomiting on several occasions and loss of appetite. His head would swim at times so that he had to grasp some support to prevent his falling and he always felt drowsy although he did not sleep well at night. He was quite clear that he had not lost flesh at all nor had he suffered from actual syncope. For three weeks he had been constipated and had a burning pain about the anus upon defecation the result of a fissure of recent origin. He had also had difficulty in micturition for the last few months and had to get up four or five times each night to micturate; the quantity of urine was subnormal, the specific gravity being low. There was no urethral trouble.

As he lay in bed the patient seemed to be in fair condition; his eyes were bright and his face was not wasted. There was no anæmia of the mucous membranes. His muscles were well developed and fairly firm, but very feeble in their action. His grip was weak. His skin was perhaps a little brown and this was rather more marked over his left elbow, but there was no excessive pigmentation at points of pressure. On examining his mouth, however, small spots of brownish pigment were seen all over the palate and the mucous membrane of the cheeks was affected with an almost black staining, while that of the lips was of a bluish-black colour. The area of cardiac dulness was diminished and the heart's impulse was scarcely perceptible, whilst the heart 